\title{
PROTECTION OF ENVIRONMENT BY THE USE OF FLY ASH IN ROAD CONSTRUCTION
}

\author{
P. ESKIOGLOU ${ }^{1, *}$ \\ N. OIKONOMOU ${ }^{2}$
}

Received: 29/09/06

Accepted: 27/11/07

\author{
${ }^{1}$ Aristotle University of Thessaloniki \\ Department of Forestry and Natural Environment \\ 54124, Thessaloniki, Greece \\ ${ }^{2}$ Aristotle University of Thessaloniki \\ Department of Civil Engineering \\ 54124, Thessaloniki, Greece \\ *to whom all correspondence should be addressed: \\ e-mail: pxeskio@for.auth.gr
}

\begin{abstract}
Fly ash is an important industrial by-product that comes from the combustion of coal, for the production of electrical energy. In our country, only a small percentage is used for the construction of technical projects, while the rest is stockpiled, causing serious problems. Because of its great availability and its low cost, further possibility of its usage should be investigated. In the present assignment, clay soils, natural and crushed sand-gravel were stabilized with different quantities of fly ash, for the creation of durable forest roads.

From research, it has been found that stabilization with fly ash, improves the natural and mechanical characteristics of soils (plasticity, compressive strength and particle size distribution). As a result, the improvement of the forest road networks from one side and the economy in natural inert materials and the exploitation of fly ash from the other, the importance of such an intervention in the protection of the forest ecosystem and the natural environment in general are obvious.
\end{abstract}

KEYWORDS: Stabilization of soils, crushed and natural sand-gravel

\section{INTRODUCTION - POSITION OF THE PROBLEM}

One of the most interesting by-products of the production processes, is fly ash (F. A.), a fine grained residue of coal combustion in Thermal Production Stations of Electrical Energy, the usage of which has gained greater importance the moment the preservation of natural resources, the economizing of energy and the increase of environmental sensitivity and viable growth, has become an international issue.

Internationally, fly ash has been used in many applications (ASCE, 1993; Linn and Symons, 1988) for several years, always aiming at the most beneficial end use and the protection of the environment (EC, 2000; European Committee for Standardization, 2000).

Through the stabilization of soils of high plasticity with fly ash, it has been found that not only mechanical properties were improved, compressive and shear strengths were increased and the volume expansion of soil was controlled, but also a financially viable and durable pavement was created (Querol et al., 1996).

In Greece, the annual production reaches 12 million tones, a percentage of which was used in road and soil construction, in the stabilization-improvement of soils, in the construction of embankments and mostly in the creation of new construction materials, as an addition to cement/concrete (Ftikos and Tsimas, 1985).

As a result of soil stabilization with fly ash, compression strength and plasticity were improved, while it was proven that ash can be used successfully as an additive for the base and sub-base layer construction of pavement, as well as for the construction of embankments in compressed soils (Christoulas et al., 1983; Mouratidis, 2004; Kolias and Karahalios, 2005). 
Other researchers have proven that the mixtures of ash with inert materials reach $50 \%-70 \%$ of the strength of the corresponding mixtures of cement-inactive materials (Mouratidis, 2004), while the addition of ash reduces the necessary pavement thickness and, at the same time, the construction cost (Kolias and Karahalios, 2005).

In the laboratories of the Confederacy Polytechnic School of Zurich (ETH), after research on the enforcement of subordinate sand-gravel paving with ash and cement, it appeared that its strength was improved about $40 \%$, while its average deflection under the influence of circulating masses decreases about 35\% in relation to the natural soil (Eskioglou et al., 1996). Finally, soil stabilization with the mixture of $30 \%$ ash and $8 \%$ lime decreased the deflection rate of the stabilized layer about 1,7 times in comparison to the deflection of natural soil (Eskioglou and Efthymiou, 1996).

Considering all of the above, it is attempted, in the present assignment, to investigate the possibility of clay soil stabilization and the crushed, natural, sand-gravel stabilization with various quantities of ash, so that any alteration of their mechanical properties can be recorded, to the benefit of economy and environmental protection.

\section{METHOD AND RESEARCH MATERIALS}

The research took place in the Laboratories of Public Works of Central Macedonia, and the materials used were Ptolemaida ash from the steam electrical station in Kardia, clay soils and natural sand-gravel from the University forest of Pertouli, and finally, crushed sand-gravel from the quarry of Trikala. The geological ground of the research area is mostly flysch and the soils that were studied are instable clay with low bearing capacity. Through the method of random specimen collection, the excavation positions were selected, and 20 , in total, soil specimens were collected. For every soil specimen there was a particle size distribution analysis, calculation of the Atterberg limits, compaction with the modified AASHTO T-180 method, definition of optimum moisture content $\mathrm{w} \%$ and the corresponding dry density $\mathrm{V}_{\mathrm{d}}$ (AASHO, 1986; 1987).

Then the stabilization of the soil and sand-gravel specimens with ash in various percentages followed. Change of soil plasticity under the effect of ash in various percentages was measured, while change in the Proctor rates was calculated and the unhindered compressive strength was computed after a sample curing for 7, 28 and 90 days. The cylindrical soil samples, of dimensions $50 \times 100 \mathrm{~mm}$, were prepared with optimum moisture content and were statically compacted, according to the B.S.-1924/1975 method, testing 10 (British Standards, 1975).

\section{RESULTS}

Ptolemaida ash, which was used in our research, is characterized by a high $\mathrm{CaO}$ percentage that permits its use in clay soil stabilization. From its particle size distribution analysis, it was found that $92 \%$ of its weight passes through sieve No $200(75 \mu \mathrm{m})$, something that indicates the hydraulic and pozolanic properties.

Table 1 presents the Atterberg limits, the Proctor rates and the particle size distribution of the studied soil, while table 2 shows the particle size distribution of sand-gravels. By the classification of the soil specimens it was found that they are limited in 2 categories, the $\mathrm{CL}$ (two types I and II) and $\mathrm{CH}$ (two types I and II).

Table 1. Atterberg limits, optimum moisture content, maximum dry density and particle size distribution of research soils

\begin{tabular}{lccccccccc}
\hline $\begin{array}{l}\text { Type } \\
\text { of soil }\end{array}$ & LL & PI & W\% & $\begin{array}{c}\text { Ydopt } \\
\left(\mathbf{k g ~ m}^{-3}\right)\end{array}$ & No 4 & No 10 & No 40 & No 100 & No 200 \\
\hline $\mathrm{CL} \mathrm{I}$ & 40.3 & 21.3 & 16 & 1800 & 97 & 96 & 92 & 80 & 60 \\
\hline $\mathrm{CH} \mathrm{I}$ & 64 & 39 & 19 & 1600 & 95 & 92 & 88 & 79 & 68 \\
\hline $\mathrm{CL} \mathrm{II}$ & 47 & 24 & 15 & 1750 & 98 & 92 & 78 & 70 & 65 \\
\hline $\mathrm{CH}$ II & 58 & 30 & 20 & 1650 & 89 & 87 & 80 & 77 & 70 \\
\hline
\end{tabular}


Table 2. Particle size distribution of research gravel-sand (GS)

\begin{tabular}{lcccc}
\hline \multirow{2}{*}{ Sieves } & \multicolumn{4}{c}{ Particle size distribution of GS material } \\
\cline { 2 - 5 } & CrushedI (GS) & Crushed II & Natural I (GS) & Natural II \\
\hline No 4 & 57 & 53 & 57 & 50 \\
\hline No 10 & 35 & 38 & 35 & 32 \\
\hline No 40 & 18 & 19 & 30 & 27 \\
\hline No 100 & 12 & 10 & 21 & 18 \\
\hline No 200 & 5 & 6 & 17 & 13 \\
\hline
\end{tabular}

Table 3 shows the change of plastic properties of clay soils, while the change of optimum moisture content and maximum dry density was recorded in Table 4 - under the effect of various ash percentages. Finally, the change in load bearing capacity to uniaxial compression after a stabilization and curing for 7, 28 and 90 days is presented in Table 5 (every value of strength is the average value of three compression samples).

Table 3. Influence of fly-ash content on the Atterberg limits

\begin{tabular}{ccccccccc}
\hline $\begin{array}{c}\text { Fly ash } \\
\text { content (\%) }\end{array}$ & Soil & CL I & Soil & CL II & Soil & CH I & Soil & CH II \\
\cline { 2 - 9 } & IP & LL & IP & LL & IP & LL & IP \\
\hline 0 & 40.3 & 21.3 & 47 & 24.0 & 64 & 39 & 58 & 30 \\
\hline 5 & 38.0 & 20.8 & 44 & 22.0 & 58 & 34 & 53 & 27 \\
\hline 8 & 36.0 & 20.0 & 41 & 20.0 & 52 & 25 & 47 & 24 \\
\hline 10 & 34.0 & 19.4 & 37 & 18.2 & 47 & 22 & 40 & 22 \\
\hline 15 & 33.0 & 19.2 & 35 & 17.0 & 41 & 18 & 38 & 20 \\
\hline
\end{tabular}

Table 4. Variation of the moisture-density relationships of soil treated with different percentages of fly ash

\begin{tabular}{|c|c|c|c|c|}
\hline \multirow{3}{*}{$\begin{array}{l}\text { Mix of soil and } \\
\text { Fly ash }\end{array}$} & \multicolumn{4}{|c|}{ Method Proctor: variation of moisture - density realtionship } \\
\hline & \multicolumn{2}{|c|}{ Maximum dry density $\left(\mathrm{kg} \mathrm{m}^{-3}\right)$} & \multicolumn{2}{|c|}{ Optimum moisture (\%) } \\
\hline & Soil $\mathrm{CL}_{1}$ & Soil $\mathrm{CL}_{\|}$ & $\mathrm{CL}_{1}$ & $\mathrm{CL}_{\|}$ \\
\hline 4 & 1750 & 1720 & 16.5 & 15.4 \\
\hline 6 & 1720 & 1680 & 16.7 & 15.8 \\
\hline 8 & 1670 & 1630 & 17.2 & 16.5 \\
\hline 10 & 1620 & 1580 & $\overline{17.9}$ & 16.9 \\
\hline Fly ash (\%) & Soil $\mathrm{CH}_{\mathrm{I}}$ & Soil $\mathrm{CH}_{\|}$ & $\mathrm{CH}_{\mathrm{I}}$ & $\mathrm{CH}_{\|}$ \\
\hline 5 & 1580 & 1630 & 19.7 & 20.5 \\
\hline 8 & 1540 & 1600 & 20.0 & 21.4 \\
\hline 10 & 1510 & 1570 & 20.6 & 21.8 \\
\hline 15 & 1470 & 1550 & 21.0 & 22.0 \\
\hline
\end{tabular}

The optimum moisture content and maximum dry density of crushed and natural sand-gravel alteration when these specimens are stabilized with various quantities of fly ash are recorded in Table 6. Table 7 presents the change in strength after stabilization and a curing of 7,28 and 90 days.

\section{CONCLUSION-CONVERSATION}

From the study which took place the following results appear:

- The soils that were studied are not considered to be appropriate for embankments, nor for paving, foundation materials due to their plasticity. Nevertheless, the mixture of fly ash with the fine grained soil material, has improved its mechanical properties that are expressed with the Atterberg limits. It resulted in reduction of the moisture content and of the plasticity indicator, up to $34 \%$ and $50 \%$ respectively (case of $\mathrm{CH}_{2}$ soil), resulting in the soil maintaining stability while increasing the moisture content. 
Table 5. Variation of the compressive strength of soil treated with different percentages of fly ash after 7, 28 and 90 days curing

\begin{tabular}{ccccc}
\hline \multirow{2}{*}{ SOIL } & \multirow{2}{*}{ Fly-ash (\%) } & \multicolumn{3}{c}{ Strength (MPa) for different days curing } \\
\cline { 2 - 5 } & & $\mathbf{7}$ days & $\mathbf{2 8}$ days & $\mathbf{9 0}$ days \\
\hline \multirow{3}{*}{$\mathrm{CL}_{1}$} & 5 & 0.40 & 0.70 & 1.00 \\
\cline { 2 - 5 } & 10 & 0.45 & 1.10 & 1.60 \\
\cline { 2 - 5 } & 20 & 0.48 & 1.50 & 2.80 \\
\hline \multirow{3}{*}{$\mathrm{CL}_{2}$} & 5 & 0.48 & 0.70 & 1.20 \\
& 10 & 0.50 & 1.10 & 1.90 \\
\cline { 2 - 5 } & 20 & 0.57 & 1.60 & 3.10 \\
\hline \multirow{2}{*}{$\mathbf{C H}_{1}$} & 5 & 0.10 & 0.20 & 0.38 \\
& 10 & 0.30 & 0.45 & 0.60 \\
\hline \multirow{2}{*}{$\mathbf{C H}_{2}$} & 20 & 0.70 & 1.20 & 1.80 \\
\cline { 2 - 5 } & 5 & 0.20 & 0.35 & 0.65 \\
\cline { 2 - 5 } & 10 & 0.30 & 0.50 & 1.30 \\
\hline & 20 & 0.40 & 0.75 & 1.90 \\
\hline
\end{tabular}

Table 6. Variation of the moisture-density relationships of sand-gravel (crushed and natural) treated with different percentages of fly ash

\begin{tabular}{ccccc}
\hline \multirow{2}{*}{$\begin{array}{c}\text { Sand-Gravel } \\
\text { and Fly ash }\end{array}$} & \multicolumn{4}{c}{ Method Proctor: variation of moisture- density relationship } \\
\cline { 2 - 5 } & \multicolumn{2}{c}{ Maximum dry density $\mathbf{k g ~ m}^{-3}$ ) } & \multicolumn{2}{c}{ Optimum moisture (\%) } \\
\hline Fly ash (\%) & Crushed I & Crushed II & Crushed I & Crushed II \\
\hline 4 & 2238 & 2212 & 6.4 & 6.3 \\
\hline 6 & 2278 & 2275 & 7.5 & 7.1 \\
\hline 8 & 2242 & 2262 & 8.2 & 7.6 \\
\hline 10 & 2195 & 2200 & 9.1 & 8.4 \\
\hline Fly ash (\%) & Natural I & Natural II & Natural I & Natural II \\
\hline 5 & 2145 & 2154 & 5.1 & 5.6 \\
\hline 8 & 2180 & 2187 & 5.5 & 6.0 \\
\hline 10 & 2150 & 2161 & 5.9 & 6.8 \\
\hline 15 & 2123 & 2124 & 6.4 & 7.4 \\
\hline
\end{tabular}

Table 7. Compressive strength test results of fly ash - crushed and natural sand gravel mixture after 7,28 and 90 days curing

\begin{tabular}{|c|c|c|c|c|}
\hline \multirow{2}{*}{ Sand-gravel } & \multirow{2}{*}{ Fly-ash (\%) } & \multicolumn{3}{|c|}{ Strength (MPa) for different days curing } \\
\hline & & 7 days & 28days & 90 days \\
\hline \multirow{3}{*}{ Crushed I } & 5 & 4.0 & 5.0 & 7.0 \\
\hline & 10 & 5.0 & 5.8 & 7.5 \\
\hline & 20 & 5.5 & 6.3 & 7.8 \\
\hline \multirow{3}{*}{ Crushed II } & 5 & 4.0 & 5.1 & 6.0 \\
\hline & 10 & 5.0 & 6.5 & 7.0 \\
\hline & 20 & 7.5 & 8.1 & 8.3 \\
\hline \multirow{3}{*}{ Natural I } & 5 & 2.0 & 2.2 & 2.2 \\
\hline & 10 & 2.7 & 3.0 & 3.0 \\
\hline & 20 & 3.1 & 3.0 & 3.0 \\
\hline \multirow{3}{*}{ Natural II } & 5 & 2.2 & 2.3 & 2.4 \\
\hline & 10 & 3.0 & 3.2 & 3.6 \\
\hline & 20 & 3.4 & 3.5 & 3.6 \\
\hline
\end{tabular}


- The addition of ash increased the optimum moisture content in the compaction tests due to its great specific surface and decreased the maximum dry density because of its lower specific weight. This can be applied in soils that contain a high percentage of moisture resulting in greater compaction, after an evaporation of a great quantity of the contained moisture.

- The increase of the optimum moisture content contributes to the increase of the stabilized soil's capability.

- Remarkable, yet not satisfactory, was the stabilized soil specimen increase of compressive strength. It is observed that the strength increases depending on the ash percentage and the duration of the specimen curing. The largest increase is observed in soil type $\mathrm{CH}_{1}$, where for 90 days of curing, the stabilized soil with $20 \%$ ash shows 5 times greater strength compared to the soil that is stabilized with $5 \%$ of fly ash. Similarly, in the same soil specimens, with the same stabilization percentage $(20 \%)$, the strength increases about 4 times when the specimen is stabilized for 90 days, instead of 7 days. Despite of these, as it was mentioned before, the increase in strength is not satisfactory, because the load bearing capacity after stabilization is below the acceptable, according to the relevant Technical properties and classifications, value which is $17 \mathrm{~kg} \mathrm{~cm}^{-2}$, a value that can be reached only through the addition of cement or lime in the soil-ash mixture.

- On the other hand, when sand-gravels are stabilized, they present a minor increase in relation to curing period, but besides from the $10 \%$ of ash, the strength is not considerably increased. Besides this percentage, stabilization is a non economical operation and has nothing more to offer.

- Finally, it can be seen from the above that the usage of fly ash for clay soil stabilization is a successful operation that can initiate the manufacture of a construction material that can be used to help the improvement of the forest road network, with a very low cost. In combination with the use of inert materials, on one hand, and the exploitation of hazardous industrial byproducts on the other, we can understand the importance of such operation, in the protection of the Forest Ecosystems and the Natural Environment.

- The economizing, but also the competitiveness of alternative materials and byproducts, is taken for granted. The usage of these byproducts initiates the decrease of the rejected materials and storage spaces, the reduction of power consumption and the useful usage of low cost raw materials. On the other hand, the specimens used in leaching test experiments were non toxic, when there was slit or lime addition (Van der Sloot et al., 1994; Wastewater Technology Centre, 1990).

- The results, that coincide with the results of other researchers (Hilmi et al., 2006) will constitute the beginning of the stabilization application of the soil, for the construction of new, financially viable and durable pavements.

\section{REFERENCES}

1. AASHO T-180 (1986), Standard method of test for moisture-density relations of soils, AASHTO Materials , Part II, Tests.

2. AASHTO T -220-6 (1987), Standard method of test for determination of the strength of soilmixture' N.Y. USA.

3. British Standars (1975) BS 1924/1967 Stabilized materials for civil engineering purposes. General requirements, sampling, sample preparation and tests on materials before stabilization, British Standards.

4. Christoulas,S., Kollias,S. and Marsellos, N. (1983), The use of fly-ash in road construction in Greece, intervention in the 17th World Road Congress, Sydney.

5. Eskioglou, P., Hirt, R. and Burlet Ed. (1996), Investigations of pavement performance using the Benkelmann beam method, Scientific Annals of the Dept. of Forestry and Natural Environment,.LH(2), 864-876.

6. Eskioglou P., and Efthymiou P.N. (1996), Alternative stabilization methods of forest roads for an efficient and gentle mechanization in forestry, ECE / FAO / ILO Seminar, Sinaia, 96103.

7. European Commission (2000), Radiation Protection 112: Radiological protection principles concerning the natural radioactivity of building materials, Luxemburg. 
8. European Committee for Standardization (2000), EN 1097- 6.Tests of mechanical and Physical properties of aggregates, Part 6, Determination of particle density and water absorption.

9. ASCE (1993), Fly ash for soil improvement, Geotechnical Special Publication No 36, American Society of Civil Engineering, New York.

10. Ftikos Ch., Tsimas S.(1985), Investigation of the possible utilization of Greek Fly Ash, Greek Technical Chamber, Department of Chemical Engineering, Athens

11. Hilmi, A. and Aysen M. (2006), Analyses and design of a stabilized Fly ash as Pavement base material, Fuel, 85(16), 2359-2370.

12. Kolias S., Karahalios A. (2005), Analytical design of pavements incorporating a capping layer of stabilized soil with high calcium fly ash and or cement, Proceedings of the 1 rst Conference for the Utilization of Industrial By products in Building Construction, Thessaloniki, 37-46.

13. Linn, M.D. and Symons M.G. (1988), Lime-Fly ash stabilisation of fine grained soils, Australian Road Research, 18(3), 53-161.

14. Mouratidis A.(2004), Stabilization of pavements with fly-ash, Proceedings of the Conference on Use of industrial by-products in road construction, Thessaloniki, 47-57.

15. Querol X., Juan R., Solder A.L., Turiel J., and Ruiz C. (1996), Mobility of trace elements from coal and combustion wastes, Fuel, 75, 821-837.

16. Tsohos G. (2004), Utilization of by products and alternative materials in road construction, Proceedings of Conference on Use of industrial by-products in road construction, Thessaloniki, 7-15.

17. Van der Sloot, H.A., D.Hoede, R.N.J. Comans (1994), The influence of Reducing Properties on Leaching of Elements from Waste Materials and Construction Materials, Environmental Aspects of Construction with Waste Materials, 483-490, Elsevier Science.

18. Wastewater Technology Centre (1990), Compendium of Waste Leaching Tests, Environmental Protection Series, Report EPS 3/HA/7, Environment Canada, Ottawa, Canada. 